\title{
Presencia de rotavirus durante un proceso de compostaje. Abonos como vectores de contaminación viral
}

\author{
María Fernanda Gutierrez ${ }^{1 *}$, María del Pilar Bonilla ${ }^{2}$, Adriana Espinosa ${ }^{2}$, Mariela \\ Mosquera $^{2}$, Sandra Solano ${ }^{2}$, María Mercedes Martínez ${ }^{2}$ \\ ${ }^{1}$ Grupo de Enfermedades Infecciosas, ${ }^{2}$ Grupo de Biotecnología Ambiental e Industrial, Departamento de Microbiología, \\ Facultad de Ciencias, Pontificia Universidad Javeriana. Cra 7 \# 43-82, Bogotá, D.C., Colombia \\ *mfgutier@javeriana.edu.co
}

Recibido: 17-03-2009; Aceptado: 13-11-2009

\begin{abstract}
Resumen
Objetivo: Demostrar la presencia de Rotavirus en las diferentes fases de un proceso de compostaje: matrices utilizadas como materia prima, mezcla a compostar y producto terminado. Materiales y métodos. El Rotavirus se determinó durante los tres procesos de compostaje. La detección viral se realizó por inmunocromatografía, ELISA y RT- PCR. Resultados. Se evidenció presencia viral en el primer proceso de compostaje, ausencia viral en el segundo y en el tercer proceso de compostaje, se presentaron interferencias que dificultaron interpretar los resultados de la PCR, lo cual impidió llegar a un resultado concluyente de su presencia en el abono. Conclusiones. Los abonos orgánicos pueden ser portadores de virus motivo por el cual se deben implementar pruebas de calidad para evitar que este material contribuya con la diseminación viral. Dentro de estos abonos existen sustancias capaces de interferir en las pruebas de detección
\end{abstract}

Palabras clave: Abonos, compostaje, inhibidores de la PCR, Rotavirus

\begin{abstract}
Rotavirus presence in a waste composting process. Organic fertilizers as vehicles for viral contamination. Objective. To show the presence of rotavirus in different stages of a composting process: matrices used as raw material, mixture to be composted and the final product. Materials and methods. Immunochromatography, ELISA and RT-PCR were used for viral detection. Results. Rotavirus was found in the first composting step, no virus was found in the second step, and some inhibitory substances were found in the third step that posed difficulties in interpreting the PCR results and therefore providing a concluding result on rotavirus presence in the final product. Conclusions. Organic fertilizers can be vectors of human pathogenic viruses; therefore quality control tests must be implemented to avoid further viral dissemination. There are inhibitory substances present in organic fertilizers capable of interfering with the detection tests.
\end{abstract}

Key words: composting, organic fertilizers, PCR inhibitors, rotavirus 


\begin{abstract}
Resumo
Presença de rotavírus durante um processo de compostagem. Adubos como vetores de contaminação viral. Objetivo. Demonstrar a presença de Rotavírus nas diferentes fases de um processo de compostagem: matrizes utilizadas como matéria-prima, mistura de composto e produto final. Materiais e métodos: A determinação do Rotavírus foi realizada nos três processos de compostagem. A detecção viral foi realizada por imunocromatografia, ELISA e RT-PCR. Resultados. Evidenciou-se a presença viral no primeiro processo de compostagem, ausência de vírus no segundo, e no terceiro processo de compostagem, apresentaram-se interferências que dificultaram a interpre tação dos resultados da PCR, tornando impossível chegar a um resultado conclusivo de sua presença no adubo. Conclusões. Os adubos orgânicos podem abrigar o vírus é por isso que se devem implementar provas de qualidade para evitar que esse material contribuía com a disseminação viral. Dentro desses fertilizantes existem substâncias capazes de interferir nas provas de detecção.
\end{abstract}

Palavras-chave: fertilizantes, compostagem, os inibidores da PCR, rotavírus

\section{Introducción}

El hombre y los animales excretan diariamente por materia fecal un gran número de virus los cuales se depositan directamente en el suelo, el agua, servicios de alcantarillado, contaminando el medio ambiente, aguas, lodos, pastos, suelo, e inclusive, los vegetales que crecen en terrenos expuestos a abonos o agua contaminada. Brotes de enfermedades asociadas con patógenos presentes en aguas, frutas, verduras y jugos no pasteurizados han sido descritos en varios países, lo cual ha generado una voz de alerta a las autoridades sanitarias para el control principalmente de aguas o alimentos que podrían servir como vectores y contribuir con la diseminación y la llegada de virus a sus huéspedes naturales, en este caso, el hombre (1).

Los abonos, en especial los de origen animal y los biosólidos provenientes del proceso de tratamiento de aguas residuales poseen un alto contenido de materia orgánica que puede ser utilizado en agricultura para aportar macro y micronutrientes; a la vez contiene numerosos microorganismos patógenos como virus entéricos que al estar presentes en la materia prima, pueden asociarse con diarrea, meningitis, y hepatitis en individuos susceptibles (2). La presencia viral en matrices sólidas tipo lodo o biosólido se facilita por la adsorción preferencial de estos en la material orgánica, donde los virus forman agregados, lo que les permite prolongar su actividad infecciosa y convierte estas matrices en fuente de contaminación viral para el agua, el suelo y alimentos (3).

El Rotavirus (RV) es considerado el principal agente etiológico de diarreas, asociado con 114 millones de episodios de diarrea por año lo que lleva a cerca de 24 millones de consultas médicas, 2,4 millones de hospitalizaciones y cerca de 500.000 muertes en niños menores de 5 años (4). Este virus es excretado en personas infectadas en cantidades de aproximadamente $10^{10}$ partículas por gramo de materia fecal $(5,6)$. Dentro de sus características se ha reportado que resiste rango de $\mathrm{pH}$ entre 3 a $9 \pm 0,2$, temperatura de $40^{\circ} \mathrm{C}$ por varios días y de $20^{\circ} \mathrm{C}$ por varias semanas, cuando se mantiene en 1,5 mM de calcio y que la partícula completa mantiene su integridad e infectividad cuando es tratada con solventes orgánicos tales como éter, cloroformo o freón, lo que permite inferir la ausencia de lípidos en su estructura. No es claro cómo la dureza del agua (iones calcio y magnesio) contribuye con la capacidad del virus para penetrar en las células del hospedero, aunque se sabe que ayudan a mantener la integridad viral, estabilizando la cápside externa y manteniendo la capacidad infecciosa (7). Por otra parte, los cationes bivalentes y trivalentes favorecen la agregación viral contribuyendo con su estabilidad $(2,8)$.

Sin embargo, hay varios factores ambientales que logran disminuir la infectividad viral como por ejemplo altas concentraciones de formalina, cloro, betapropiolactona y etanol al 95\%. El cloro en el agua potable altera las proteínas de la cápside externa del RV y su incremento favorece la dispersión de agregados virales (7-9). Asi mismo, cuando el $\mathrm{pH}$ natural del medio aumenta, la capacidad de infección se reduce, al permitir que las partículas que conforman el agregado viral queden expuestas a otros factores presentes en el medio (7). Sustancias tales como la cal, alcalinizan el medio lo que permite que los iones $\mathrm{NH}_{4}^{+}$pierdan un protón produciéndose gas amoniaco y la combinación entre el alto pH y el amonio logra reducir el título viral debido a que fragmenta el RNA. Igualmente, otro de los factores ambientales que bajan el título viral dentro de un soporte orgánico como compost o biosólidos es la desecación, pues la ausencia de agua disminuye la estabilidad a las moléculas constitutivas virales (2).

Dentro de las cadenas productivas de frutas (10) y verduras, los abonos orgánicos, sean de origen animal, vegetal o mixto han tomado gran interés debido a su aporte de materia orgánica, concentración de microflora benéfica y en algunos casos, la baja toxicidad y poca capacidad de contaminar el medio ambiente. Estos materiales que se producen por procesos como lombricultura o compostaje tienen 
como valor agregado el aprovechamiento de residuos agroindustriales, vegetales, animales o provenientes de plantas depuradoras, pero por otro lado, pueden contener microorganismos y virus que podrían llegar a los consumidores en caso de no ser degradados durante el proceso de producción del compost (11).

Por la ausencia de envoltura y la presencia de tres capas proteicas dentro de la estructura del RV, se podría suponer que este es parcialmente resistente a efectos del medio ambiente, sin embargo su título debería disminuir al estar expuesto a las condiciones de temperatura y $\mathrm{pH}$ alcanzadas durante un proceso de compostaje. Durante este trabajo se quiso demostrar el comportamiento viral a lo largo del proceso de compostaje para determinar el papel que tiene el abono como posible vehiculo de transporte viral.

\section{Materiales y métodos}

\section{Preparación del material orgánico y proceso de compostaje}

La determinación de RV se llevó a cabo durante tres procesos de compostaje realizados en diferentes años y épocas del año, dos de ellos con residuos del relleno sanitario "Don Juanito" en la ciudad de Villavicencio manejado por la empresa Bioagrícola del Llano S.A. y el tercero con residuos de la planta de tratamiento de agua de El Salitre (PTAR "El Salitre"), en Bogotá. Cada uno de estos procesos, será llamado "ensayo" y para cada ensayo se realizaron distintos procedimientos que serán llamados "tratamientos". El primer ensayo se realizó en los meses de noviembre-diciembre de 2006, con el que se buscaba determinar la proporción en la que se debía preparar la mezcla a compostar, el segundo ensayo se realizó en los meses de junio-julio de 2007, para el cual se utilizó la mezcla seleccionada en el primer ensayo. El tercer ensayo utilizó materias primas diferentes y se realizó en los meses de agosto y septiembre del 2007. Los tratamientos realizados a cada ensayo se repitieron tres veces, en tres pilas y de manera simultanea.

Para los dos primeros ensayos, el material a compostar se preparó con cuatro materias primas: cascarilla de arroz, cortes de pasto y material vegetal, residuos de la plaza de mercado y contenido ruminal.

Para el primer ensayo se prepararon dos tratamientos, uno con una mezcla que contenía $50 \%$ de residuos de plaza y $20 \%$ cortes de pasto, en el segundo tratamiento la mezcla contenía $60 \%$ de residuos de la plaza y $10 \%$ de cortes de pasto. Ambos tratamientos tenían $20 \%$ contenido ruminal y $10 \%$ de cascarilla de arroz. El segundo ensayo se corrió con la mezcla que en el primer ensayo, presentó mejor resultado respecto a la temperatura máxima alcanzada en el proceso y características fisicoquímicas durante el compostaje. Para el tercer ensayo se utilizaron cuatro tratamientos. Las materias primas utilizadas fueron cortes de pasto kikuyo, cascarilla, biosólido y un inóculo termofílico acelerador del proceso de compostaje.

Los cuatro tratamientos del tercer ensayo fueron elaborados con distintas mezclas: en el primero tratamiento se utilizó pasto, cascarilla, biosólido e inóculo PUJ (preparado en la Universidad Javeriana en Bogotá). En el segundo tratamiento, se utilizó pasto, cascarilla, biosólido e inóculo nativo, en el tercer tratamiento biosólido, cascarilla y pasto y el cuarto tratamiento sólo contenía biosólido.

El proceso de compostaje duró 8 semanas tanto para los residuos de plaza como para el biosólido. El muestreo se realizó semanalmente recogiendo en bolsa plástica $500 \mathrm{~g}$ de muestra a partir de cinco diferentes secciones de cada pila el cual fue almacenado a $-20^{\circ} \mathrm{C}$ hasta su procesamiento. De estos $500 \mathrm{~g}, 5 \mathrm{~g}$ del material fue utilizado para la determinación viral. En cada pila de compostaje se determinó la temperatura aleatoriamente en 5 puntos diferentes utilizando un termómetro de punzón de $70 \mathrm{~cm}$ de largo con receptor digital de datos. Ésta se midió internamente enterrando el termómetro completamente en la pila de compost. La medición fue realizada semanalmente por ocho semanas. El pH fue determinado mediante el método de pasta de saturación, de acuerdo a la norma ICONTEC 2004, que consiste en tomar cinco submuestras de cada pila, completando 500g. Posteriormente se agregan $500 \mathrm{~mL}$ de agua destilada, se homogeniza y sedimentada por $5 \mathrm{~min}$. tomando el valor de $\mathrm{pH}$ sobre el extracto líquido superficial

\section{Extracción y concentración del virus a partir de las muestras}

La técnica utilizada para la extracción del agente viral, fue la técnica de elusión descrita por Ahmed y Sorensen 1995 y modificada para este trabajo. Para tal fin se diluyeron 5 gr. de compost y de cada materia prima en $30 \mathrm{ml}$ de extracto de carne al $10 \%(\mathrm{pH} 9 \pm 0,2))$ los cuales fueron sometidos a agitación en vórtex, diez veces por 1 minuto. La mezcla se llevó a sonicación en hielo a $37 \mathrm{~Hz}$ por 5 minutos con intervalos de un minuto, seguido de una agitación por 5 minutos a $500 \mathrm{rpm}$. La suspensión resultante fue centrifugada a $5000 \mathrm{~g}$ por 1 hora a $4^{\circ} \mathrm{C}$. El pH del sobrenadante fue ajustado a 7,2 $\pm 0,2$ con $\mathrm{HCl} 1 \mathrm{M}$. 
La técnica utilizada para la concentración de la partícula viral fue la descrita por Lewis y Metcalf 1988 y modificada por Mignotte y colaboradores (12). Al sobrenadante obtenido de la extracción se le adicionó polietilenglicol 6000 (PEG 6000) en tampón fosfato $\mathrm{pH} 7,2 \pm 0,2$ hasta una concentración de $8 \%(\mathrm{p} / \mathrm{v})$. La mezcla fue llevada a agitación por $1,5-2$ horas a $4^{\circ} \mathrm{C}$ a $150-200 \mathrm{rpm}$ y conservada a $4^{\circ} \mathrm{C}$ durante toda la noche para posteriormente centrifugarla a $5000 \mathrm{~g}$ por 90 minutos a $4^{\circ} \mathrm{C}$. El precipitado fue suspendido en 2,5 ml de PBS pH 7,2 $\pm 0,2$ (13).

\section{Control de proceso de extracción, purificación y determinación de virus}

Teniendo en cuenta que el procedimiento de extracción, purificación y detección de virus a partir de compost no ha sido ampliamente reportado, la estandarización exigió verificar los procedimientos. Para tal fin $5 \mathrm{~g}$ de compost se mezclaron con $1 \mathrm{ml}$ de materia fecal positiva para $\mathrm{RV}$ (gentilmente donada por el Instituto Nacional de Salud), la mezcla se dejó a temperatura ambiente por 24 horas y se procedió a realizar el proceso completo de extracción, purificación y detección de virus, tal y como se procesaron las muestras estudiadas. La determinación de la presencia viral se realizó por diferentes técnicas a los distintos ensayos. A los primeros dos ensayos se les aplicaron las pruebas de Inmunocromatografía y ELISA que son pruebas que detectan presencia de antígenos virales. Al tercer ensayo se le determinó la presencia viral con la prueba de RT-PCR que determina la presencia de segmentos génicos virales. El motivo de cambio de técnica fue la búsqueda de una mayor sensibilidad en la detección de la presencia viral.

\section{Detección de Rotavirus por Inmunocromatografía (ICF)}

Para los dos primeros ensayos y para los controles de estos, la presencia viral se determinó mediante una prueba de Inmunocromatografìa (ICF) (VIKIA ${ }^{\circledR}$ Rota-Adeno) que detecta de manera simultánea la presencia de RV y Adenovirus. La prueba se realizó siguiendo las instrucciones del fabricante. La presencia de una línea azul en el estuche fue interpretada como prueba positiva para la presencia viral. Los controles positivos y negativos de esta prueba venían incluidos desde la casa comercial.

\section{Detección del Rotavirus por prueba de ELISA}

Esta prueba de ELISA sólo fue aplicada a los 9 controles y 36 muestras seleccionadas por conveniencia dentro de muestras recolectadas en el primer ensayo. Para esta detección se utilizó el kit de ELISA PATHFINDER ROTAVIRUS (BIORAD $\AA$, 2006) empleado usualmente para detectar este virus en heces humanas (14) y el procesamiento se realizó siguiendo las instrucciones del fabricante. La lectura se hizo a $450 \mathrm{~nm}$. El punto de corte se definió como el valor de absorbancia del control negativo al que se le adicionó 0,075 . Las absorbancia que sobrepasaron este valor fueron consideradas positivas. Los controles positivos de esta prueba venían incluidos dentro del estuche

\section{Detección de Rotavirus por prueba de RT- PCR}

Para determinar la presencia de RV en el tercer ensayo y en sus controles, se realizó la amplificación de un segmento del gen de VP6 (proteína de cápside interna). La amplificación de este segmento se realizó en dos pasos, el paso de retrotanscripción donde se utilizó la enzima MML- $\mathrm{V}$ y random primer, para esto se llevó a incubar por 5 minutos a $97^{\circ} \mathrm{C}$, $42^{\circ} \mathrm{C} 1$ hora y $95^{\circ} \mathrm{C}$ por 5 minutos. Los cebadores que se usaron amplifican una región de 379-bp desde el nucleótido 747 al 1126 y son el VP6-F en sentido positivo, (nt 747-766, 5' GACGGVGCRACTACATGGT 3') y VP6-R en sentido negativo, (nt 1126-1106, 5' GTCCAATTCATNCCT GGTGG $3^{\prime}$ ). El proceso de amplificación se realizó a $94^{\circ} \mathrm{C}$ por 2 minutos, $94^{\circ} \mathrm{C}$ por 30 segundos, $58^{\circ} \mathrm{C}$ por 30 segundos, $72^{\circ} \mathrm{C}$ por 1 minuto, 40 ciclos y una extensión final a $72{ }^{\circ} \mathrm{C}$ por 7 minutos (10).

La detección de RV se realizó también al pasto, a la cascarilla, a la cascarilla a la cual se le había mezclado materia fecal positiva para RV, a la cascarilla esterilizada, al biosolido mezclado con materia fecal positiva para RV y al biosólido esterilizado.

\section{Detección de inhibidores de la prueba de PCR}

Con el objeto de descartar posibles falsos negativos en la prueba de PCR, $5 \mathrm{~g}$ de muestras de compost estéril y de muestra de uno de los tratamientos del tercer ensayo se disolvieron en $30 \mathrm{ml}$ de extracto de carne al $10 \%$ y se mezclaron con $10 \mathrm{ml}$ de materia fecal de origen humano, positiva para RV. Igualmente se tomaron muestras estériles a las que no se les añadió RV. Estas muestras fueron procesadas de igual forma que todas las anteriores para buscar la amplificación de segmentos virales. 


\section{Resultados}

\section{Presencia del Rotavirus en el material estudiado}

En el primer ensayo, la prueba se ICF se realizó a 47 de las 48 muestras tomadas y se encontraron 7 muestras positi- vas para presencia viral (Tabla 1). A este mismo ensayo se le realizó prueba de ELISA a 36 de las 48 muestras tomadas, encontrando 11 muestras positivas (Tabla 2). En el segundo ensayo todas las muestras fueron negativas para $\mathrm{RV}$, tanto las materias primas como los productos finales. De las cuatro matrices utilizadas en los primeros dos ensayos, la presencia viral se hizo evidente únicamente en el contenido ruminal (Tabla 3).

Tabla 1. Resultados de la presencia de RV en muestras de compost del primer ensayo por prueba de Inmunocromatografía.

\begin{tabular}{lcccccc}
\hline Semana & \multicolumn{3}{c}{ Tratamiento 1 } & \multicolumn{5}{c}{ Tratamiento 2 } \\
\hline & Pila* 1 & Pila 2 & Pila 3 & Pila 1 & Pila 2 & Pila 3 \\
\hline 1 & + & + & + & $\mathrm{Nr}$ & + & + \\
2 & + & - & - & - & - & - \\
3 & - & - & - & - & - & - \\
4 & - & - & - & - & - & - \\
5 & - & - & - & - & + & - \\
6 & - & - & - & - & - & - \\
7 & - & - & - & - & - & - \\
8 & - & - & - & - & - & - \\
\hline
\end{tabular}

Nr: no se realizó detección viral en esa muestra. *Cada pila constituye una replica idéntica del tratamiento.

Tabla 2. Presencia de RV por prueba de ELISA en el primer ensayo.

\begin{tabular}{lcccccc}
\hline & \multicolumn{3}{c}{ Tratamiento 1 } & \multicolumn{3}{c}{ Tratamiento 2 } \\
\hline Semana & Pila 1 & Pila 2 & Pila 3 & Pila 1 & Pila 2 & Pila 3 \\
\hline 1 & 1,259 & 1,346 & 1,273 & 1,527 & 1,483 & 0,534 \\
2 & 0,087 & 0,046 & 0,496 & 0,001 & 0,001 & 0,001 \\
3 & 0,001 & 0,005 & 0,001 & 0,009 & 0,001 & 0,001 \\
4 & 0,001 & 0,001 & 0,041 & 0,075 & 0,093 & 0,092 \\
5 & 0,086 & 0,061 & 0,006 & 0,074 & 0,187 & 0,08 \\
6 & $\mathrm{Nr}$ & $\mathrm{Nr}$ & $\mathrm{Nr}$ & $\mathrm{Nr}$ & $\mathrm{Nr}$ & $\mathrm{Nr}$ \\
7 & $\mathrm{Nr}$ & $\mathrm{Nr}$ & $\mathrm{Nr}$ & $\mathrm{Nr}$ & $\mathrm{Nr}$ & $\mathrm{Nr}$ \\
8 & 0,067 & 0,208 & 0,064 & 0,027 & 0,149 & 0,207 \\
\hline
\end{tabular}

Se consideró positivo aquel valor de absorbancia superior a 0,140. Nr: no se realizó detección en esa muestra. 
Tabla 3: Resultado de la presencia de RV en las materias primas. Prueba de Inmunocromatografía.

\begin{tabular}{ccccc}
\hline Materias primas & Cascarilla de arroz & Podas & Contenido Ruminal & Residuos de Plaza \\
\hline ELISA & Negativo & Negativo & Positivo & Negativo \\
\hline ICT & Negativo & Negativo & Positivo & Negativo \\
\hline
\end{tabular}

\section{Curvas de temperatura y pH durante los dos primeros ensayos}

La temperatura durante el proceso de los dos primeros ensayos se comportó siguiendo el modelo de los procesos de compostaje donde se diferencian claramente tres fases correspondientes a mesofílica durante los primeros días, con temperaturas entre 35 y $60^{\circ} \mathrm{C}$, termofílica con rango de temperatura entre 50 y $70^{\circ} \mathrm{C}$ a partir del día 5 de proceso hasta la semana 6 y posteriormente una mesofílica nuevamente que se evidenció hasta el final del proceso. Respecto al $\mathrm{pH}$ igualmente el comportamiento respondió con una etapa inicial de acidificación leve, con descenso del pH hasta $6,0 \pm 0,2$ y posterior alcalinización hasta $8,0 \pm 0,2$, manteniéndose así hasta el final del proceso.

\section{Verificación del proceso de extracción, purificación y determinación de virus}

Con el objeto de verificar que realmente se estaba logrando extraer y purificar virus a partir del compost y verificar también la ausencia de inhibidores que generaran resultados falsos negativos en las pruebas de ELISA e ICF, una muestra de materia fecal positiva se mezcló con compost estéril. Como control negativo se utilizó compost el cual fue llevado a autoclave por 20 minutos. La detección viral que se realizó directamente con pruebas de ELISA, y los resultados se presentan en la tabla 4 .

\section{Determinación de RV en el tercer ensayo por PCR}

En este tercer ensayo se utilizó la prueba de RT-PCR para detectar un segmento de $376 \mathrm{pb}$ del gen que codifica para la proteína VP6 del RV. En el gel de agarosa se pudo observar que las muestras positivas fueron el control positivo, la muestra de pasto (Figura 1 pozo 2) y la muestra de cascarilla a la cual se le adicionó materia fecal positiva para RV, (Figura 1 pozo 4). En la cascarilla estéril (Figura 1 pozo 6) se evidencian bandas inespecíficas en el gel de agarosa, lo cual fue repetido buscando contaminación durante la fase de laboratorio. Dentro de las muestras negativas están

Tabla 4. Resultados de las pruebas de ELISA para verificar el proceso de manejo de muestras.

\begin{tabular}{lc}
\hline & Prueba de ELISA al primer ensayo \\
\hline Control positivo Kit & 2,109 \\
Control negativo Kit & 0,065 \\
Muestra de materia fecal positiva para RV & 1,967 \\
Compost con adición del Control Positivo & 1,653 \\
Compost estéril & 0,05 \\
Cascarilla de arroz & 0,051 \\
Cortes de pasto & 0,018 \\
Contenido ruminal & 1,453 \\
Residuos de Plaza & 0,085 \\
\hline
\end{tabular}

Se considera como positivo valores superiores a 0,14 . 
el control negativo, la cascarilla (Figura 1 pozo 1), una muestra del cuarto tratamiento a la cual se le agregó materia fecal positiva para RV (Figura 1 pozo 3), una muestra del cuarto tratamiento pero que había sido esterilizada en autoclave (Figura 1 pozo 5) y dos muestras más de los tratamientos uno y dos (Figura 1 pozos 7 y 8). La totalidad de las muestras de los dos ensayos fueron negativas para la presencia de RV (Figura 2).

\section{Discusión}

En el mundo se reportan anualmente billones de casos de diarrea con un aproximado de 1,8 millones de muertes cada año (14). De la totalidad de casos, el $88 \%$ se asocian con aguas contaminadas o problemas de higiene de la población. Dentro de los agentes virales que predominan en los casos de diarrea están el Rotavirus y los Norovirus

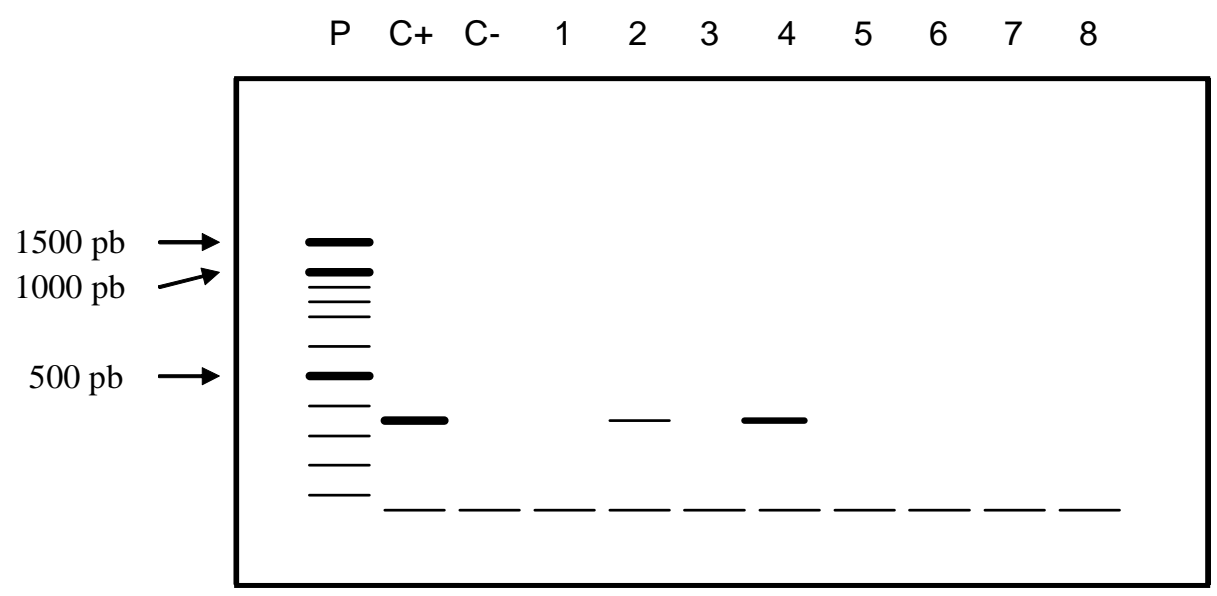

Figura 1. Resultados de la RT-PCR para el segmento de 376 pb del gen que codifica la proteína VP6 de cápside intermedia. Muestras y controles del tercer ensayo. Los tres primeros pozos contienen: Patrón de talla molecular (Promega cat \# 62101) con tres bandas resaltadas, la inferior de $500 \mathrm{pb}$, la intermedia superior de $1000 \mathrm{pb}$ y la superior de $1500 \mathrm{pb}$, y los controles de técnica de PCR: control positivo gentilmente donado por el grupo de virología del Instituto Nacional de Salud de Colombia y el control negativos una muestra diarreica previamente probada en el laboratorio de virología de la Universidad Javeriana. En lo adelante, los pozos contienen: Pozo 1: Cascarilla, Pozo 2: Cortes de pasto, Pozo 3: Mezcla del cuarto tratamiento y materia fecal positiva para RV, Pozo 4: Mezcla de cascarilla y materia fecal positiva para RV, Pozo 5: Muestra del quinto tratamiento estéril, Pozo 6 Cascarilla estéril, Pozos 7 y 8: tratamientos 1 y 2.

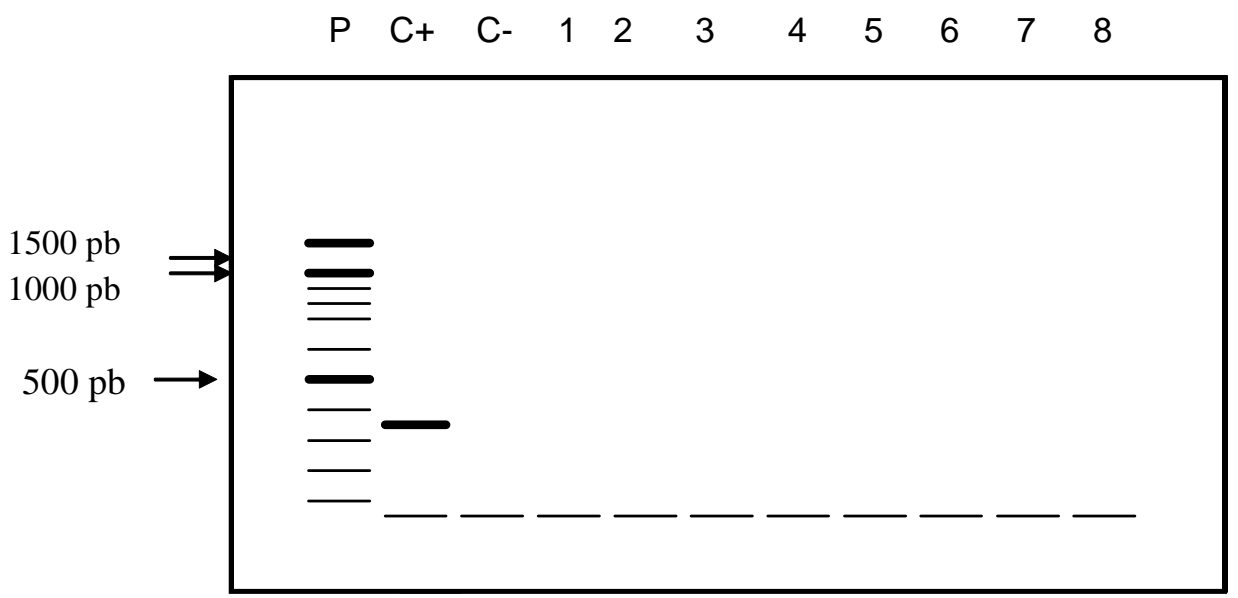

Figura 2. Resultados de la RT-PCR para el segmento de 376 pb del gen que codifica la proteína VP6 de cápside intermedia. Muestras del tercer ensayo seleccionadas al azar. Los tres primeros pozos contienen el mismo patrón de talla molecular utilizado en el gel anterior y los controles de técnica de PCR. En lo adelante, los pozos contienen: Pozos 1 al 6 contienen respectivamente T3R1, T3R2, T3R3, T4R1, T4R2, T4R3. Pozo 7: Mezcla de T4R3 y materia fecal positiva para RV, Pozo 8: T4R3 estéril. 
cuya principal vía de transmisión es fecal-oral. Por poseer resistencia a factores medio ambientales, permanecen en el suelo, el agua y los alimentos, lo que facilita su diseminación (6). Aunque existen pocos reportes donde se demuestra la presencia de virus en abonos orgánicos, es sencillo presumir que los materiales con los que estos están elaborados son fácilmente portadores de este tipo de patógenos.

Para determinar la presencia de virus en muestras biológicas existen diversas técnicas que difieren en su sensibilidad y su fundamento. En la actualidad la prueba de PCR podría considerarse como prueba de "oro para detectar el ácido nucleico viral", reportando una sensibilidad mayor a $10^{3}$ partículas/ml (15), sin embargo, su alto costo dificulta su implementación (6). La prueba de ELISA ha sido por muchos años otra alternativa para detectar virus. Esta posee una sensibilidad entre $10^{4}$ y $10^{6}$ partículas $/ \mathrm{ml}$ por lo cual, un resultado positivo significa que en la muestra deben existir cantidades iguales o mayores a esa cantidad de virus para ser detectados y un resultado negativo implica cantidades menores a $10^{4}$ partículas/ml (15).

La prueba de ICF para determinar virus en muestras biológicas ha surgido recientemente y si bien no existen datos por parte de la casa comercial de su nivel de detección, con los resultados de este ensayo se logró percibir que posee una sensibilidad menor que una prueba de ELISA, lo que supondría que detecta a partir de $10^{6}$ partículas $/ \mathrm{ml}$.

Las pruebas de ELISA y de ICF son pruebas cualitativas, sin embargo, los datos de absorbancia de la prueba de ELISA fueron utilizados por los autores como un índice del número de partículas virales. Al observar el comportamiento el RV durante el primer ensayo, se evidenció que los controles positivos sobrepasan las 1,5 unidades. En la primera semana los valores están entre 1 y 1,5 unidades y para la semana 2 los valores ya están cercanos al punto de corte, lo cual hace sospechar de una disminución progresiva de la cantidad de partículas virales. En el segundo ensayo, no se observó presencia viral en el contenido ruminal ni en otra de las matrices a compostar, lo que hace suponer que durante el proceso de compostaje, no se encontrarían resultados positivos (datos no mostrados)

Por las características de resistencia del virus a los factores medioambientales, durante la primera semana del proceso, las muestras se mantuvieron positivas pues aún no se alcanza la temperatura ni el cambio de $\mathrm{pH}$ suficiente para la destrucción viral. En la segunda semana, solo una muestra dio positiva, lo cual demuestra que los proceso químicos y físicos activos, estaban afectando la viabilidad viral, para las semanas 3 y 4 , la totalidad de las muestras fueron nega- tivas, lo cual indica que ya el proceso había logrado la inactivación viral y la desaparición la proteína VP6. La reaparición viral en la semana 5 y 8 puede ser interpretado de dos formas, la primera podría ser la contaminación del compost por herramientas de trabajo, la segunda que realmente haya existido virus durante todo el proceso de compostaje pero que por cuestiones del azar en la recolección de los $5 \mathrm{~g}$ recogidos para el tratamiento y detección viral, no se haya seleccionado un lugar en el que estuviera el virus. (distribución desigual del virus en la muestra).

En el tercer ensayo, la presencia de RV en el pasto puede considerarse como la fuente de contaminación del compost. Sin embargo la presencia de inhibidores de la PCR se hizo evidente al mezclar el RV con una muestra de compost estéril. Así pues, no se pudo saber si la ausencia de RV en los diferentes tratamientos del tercer ensayo se debió a inactivación viral por el proceso de compostaje o que realmente el virus se encuentra aun en la mezcla pero que no fue permitida la amplificación del segmento génico debido a las sustancias químicas que impidieron su amplificación. El mecanismo de acción de los inhibidores actúa en varios niveles: interfieren en la extracción del ácido nucleico, degradan las cadenas de ácido nucleico extraído, inhiben la acción de las polimerasas durante la amplificación o interaccionan con los dNTPs y el Mg del tampón de PCR impidiendo la polimerización $(3,16)$.

Con los resultados encontrados, se pueden presentar varias discusiones, la primera es que los estuches comerciales utilizados, no son exclusivos para determinar RV humano en materia fecal, estos también detectan RV de grupo A de origen bovino, sin embargo, para lograr comprobar el origen viral y poder determinar que el RV encontrado durante las primeras semanas es el mismo RV encontrado al final del mismo, se deben implementar pruebas de PCR, o PCR en tiempo real, que además de determinar la cantidad de virus presente en la muestra, darán como resultado secuencias génicas que deben ser analizadas para evidenciar similitudes de las cepas encontradas a lo largo del proceso (16).

Actualmente la norma colombiana de abonos orgánicos NTC 5167, no incluye sino bacterias patógenas en el control de calidad de los mismos, sin embargo, la decisión del gobierno francés es la de incluir en su legislación un número máximo de enterovirus en abonos orgánicos $(2,11)$, norma que ya empieza a ser estudiada por otros países de la Comunidad Económica Europea, en especial para aquellos abonos que sean aplicados para producción de hortalizas orgánicas. Con base en los resultados presentados en este artículo en donde se sugiere la presencia de virus durante un proceso de compostaje, se podría aceptar la norma 
francesa y para esto se deberán implementar técnicas de extracción y detección viral y estandarizar metodologías que detecten y eliminen sustancias inhibidoras para evitar resultados falsos negativos de virus en muestras como estas o muestras obtenidas del ambiente tales como agua, alimentos, entre otras (5). Otra de las herramientas que se debe implementar es el de las BPMs (Buenas prácticas de manejo de cultivo) en donde los utensilios de trabajo que se utilicen, sean diferentes durante cada etapa del proceso para evitar que utensilios contaminados, contaminen material limpio, que pudo ser la causa de la aparición de muestras positivas después de varias semanas en las que el RV aparentemente había desaparecido del fertilizante.

\section{Conclusiones}

Los abonos orgánicos como el compost, en especial los de origen animal o mixto, puede contribuir con la diseminación viral y que si bien el aumento de la temperatura y la presencia de productos metabólicos de los microorganismos degradadores de materia orgánica durante el proceso de compostaje deberían inactivar el virus y disminuir su título, existe la posibilidad de que estos permanezca atrapados en partículas orgánicas estables como las sustancias húmicas y lleguen luego a los cultivos, contaminado sus productos finales. Por este motivo se debe incluir la detección de virus dentro del control de calidad de los abonos y se deben implementar normas de buenas prácticas agrícolas que disminuyan la posibilidad de contaminación.

\section{Agradecimientos}

A los directivos de FIUC así como a los investigadores de las Universidades católicas de Pernambuco y Pelotas en Brasil y Universidad del Oriente en Colombia por su contribución durante el desarrollo del proyecto. Al Dr. Miguel Gassiot por ser la guía científica durante el proyecto. A los Microbiólogos Juan Ulloa, Mónica Alvarado y otros colaboradores de los laboratorios de virología y microbiología ambiental por sus aportes durante su realización.

\section{Financiación}

Este trabajo fue financiado con el proyecto FIUC, coordinado por el Centro Coordinador de la Investigación de la Federación Internacional de Universidades Católicas (CCIFIUC), dentro del proyecto titulado "Formación de Técnicos para Mejorar la Fertilidad del Suelo en Países en Vías de Desarrollo".

\section{Conflicto de intereses}

Los autores del este artículo manifiestan que el trabajo realizado y los resultados presentados no generan conflicto de intereses.

\section{Referencias}

1. Beuchat L. Vectors and conditions for preharvest contamination of fruits and vegetables with pathogens capable of causing enteric diseases, British Food Journal 2006; 108 (1): 38-53.

2. Monpoeho S, Maul A, Bonnin C, Patria L, Ranarijaona S, Billaudel S, Ferré V. Clearance of human pathogenic viruses from sludge: Study of four stabilization processes by RT-PCR and cell culture, Applied and Environmental Microbiology 2004; 70 (9): 54345440 .

3. Sano D, Fukushi K, Yoshida Y, Omura T. Detection of enteric viruses in municipal sewage sludge by a combination of the enzimatic virus elution method and RT-PCR, Water Reserach 2003; 37: 3490-3498.

4. Greenberg H, Estes M. Rotavirus: From Pathogenesis to Vaccination, Gastroenterology 2009; 136: 19391951.

5. Griffin DW, Donaldson, K.A., Paul, J.H., Rose, J.B. Pathogenic human viruses in coastal waters, Clinical Microbiology Reviews 2003; 16 (1): 129-143.

6. Bosch A, Guix S, Sano D, Pintó R. New tools for the study and direct surveillance of viral pathogens in water, Current Opinion in Biotechnology 2008; 19: 295-301.

7. Pancorbo O, Evanshen, B., Campbell, W., Lambert, S., Curtis, S., Woolley, T. Infectivity and antigenicity reduction rates of human Rotavirus strain WA in fresh waters, Applied and Enviromental Mircobiology 1987; 53 (8): 1803-1811.

8. Abad F, Pinto, R., Diez, J., Bosch, A. Desinfection of human enteric viruses in water by copper and silver in combination of low levels of chlorine., Applied and Enviromental Mircobiology 1994; 60 (7): 2377-2383.

9. Vaughn J, Chan, Y., Thomas, M. Inactivation of human and simian Rotaviruses by chlorine, Applied and Enviromental Mircobiology 1986; 51 (2): 391-394.

10. Schwarz B, Bange R, Vahlenkamp T, Johne R, Müller $\mathrm{H}$. Detection and quantitation of group A Rotaviruses 
by competitive and real-time reverse transcriptionpolymerase chain reaction Journal of Virological Methods 2002; 105: 277-285.

11. Anne-Marie P, Picard-Bonnaud F, Ferré V, Agnieszka G, Vasilica S, Gérard M. Survive of faecal indicators and enteroviruses in soil after land-spreading of municipal sewage sludge, Applied Soil Ecology 2007; 35: 473-479.

12. Mignotte B, Maul A, L S. Comparative study of techniques used to recover viruses from residual urban sludge, Journal of Virological Methods 1999; 78: 71-80.

13. Lewis G, Metcalf T. Polyethylene glycol precipitation for recovery of pathogenic viruses, including hepatitis A virus and human Rotavirus, from oyster, water, and sediment samples., Applied and Environmental Microbiology 1988; 54 (8): 1983-1988.

14. Gutierrez M, Matiz A, AA T, Parra M, M R, Mercado M. Virus diversity of acute diarrhea in tropical highlands, Revista Latinoamericana de Microbiología 2006; 8 (1): 17-23.

15. Gutierrez M, Alvarado M, Martinez E, Ajami N. Presence of viral proteins in drinkable waterSufficient condition to consider water a vector of viral transmission?, Water Research 2007; 41: 373-378.

16. Rajal V, McSwain B, Thompson D, Leutenegger C, Wuertz S. Molecular quantitative analysis of human viruses in California stormwater, Water Research 2007; 41 (19): 4287-4298. 